\title{
Balanitis Xerotica Obliterans and Its Differential Diagnosis
}

Isaac M. Neubaus and Robert A. Skidmore, MD

Background: Balanitis xerotica obliterans is a subcategory of lichen sclerosus et atrophicus limited to the male genitalia and is associated with destructive inflammation, phimosis, urethral stenosis, and squamous cell carcinoma.

Metbods: The medical literature was searched from 1983-1998 using key words balanitis, lichen, and sclerosis using the MEDLINE system.

Results and Conclusions: Balanitis xerotica obliterans can be distinguished from other genital dermatoses with similar characteristics through patient history, clinical findings, and laboratory evaluation.. Tzanck smear and cutaneous biopsy, along with a rapid protein reagin test, will provide a definitive diagnosis. Treatment with high-dose topical corticosteroids relieves symptoms, and therapy focuses on prevention of disease progression (J Am Board Fam Pract 1999;12:473-6.)

Balanitis xerotica obliterans is a subcategory of lichen sclerosus et atrophicus limited to the male genitalia. ${ }^{1}$ It is associated with destructive inflammation, phimosis, urethral stenosis, and squamous cell carcinoma. Balanitis xerotica obliterans will often be a diagnostic challenge because of the broad differential diagnosis of genital dermatoses with similar characteristics.

\section{Methods}

We describe a case of balanitis xerotica obliterans in a 26-year-old man. The clinical findings of balanitis xerotica obliterans can provide for a differential diagnosis to include infectious, rheumatic, reactive and neoplastic etiologies. A discussion of the history, symptoms, physical examination, and laboratory elements that aid in diagnosis is presented. Treatment options and preventive measures are addressed. MEDLINE was searched from 1983-1998 using key words balanitis, lichen, and sclerosis.

\section{Case Report}

A 26-year-old man was referred to the dermatology clinic for evaluation of penile lesions. He stated that areas of lighter skin on the glans and foreskin had been increasing in size during the last 2 to 3

Submitted, revised, 12 February 1999

From the College of Medicine (IMN), and the Department of Medicine (Dermatology) (RS), University of Florida, Gainesville. Address reprint requests to Robert A. Skidmore, MD, PO Box 100277, Gainesville, FL 32610. years and recounted a several year history of pruritus. Erections were associated with fissuring of the glans and shallow erosions along the foreskin. The patient was taking no medications, including laxatives or anti-inflammatory agents. The patient's medical history was noncontributory. His sexual history was negative for sexually transmitted diseases and anal receptive intercourse. He was currently involved in a heterosexual, monogamous relationship and did not use condoms. He had a lifetime history of fewer than four sexual partners. A review of symptoms was pertinent for a lack of headache, malaise, myalgias, arthralgias, or eye complaints. The patient's initial reason for seeking care was prompted by concerns of a possible herpes infection and the start of a new relationship.

On retraction of the foreskin, a discrete, white, slightly depressed $1.3-\mathrm{cm}$ patch was visible on the left glans, which extended to the edge of the meatus. (Figure 1) The foreskin was thickened, and there were $2-\mathrm{mm}$ to $3-\mathrm{mm}$ atrophic, confluent, macules. No erosions, vesicles, hyperpigmented plaques, or inguinal adenopathy were observed.

Histologic examination of a cutaneous biopsy of foreskin confirmed the diagnosis of balanitis xerotica obliterans. Therapy consisted of $0.05 \%$ clobetasol ointment applied to the glans and foreskin, initially twice daily for 3 weeks, then once every other day. The patient's symptoms of pruritus, fissuring, and erosions resolved within 7 days. A recommendation for circumcision was made, but the patient declined the procedure. 


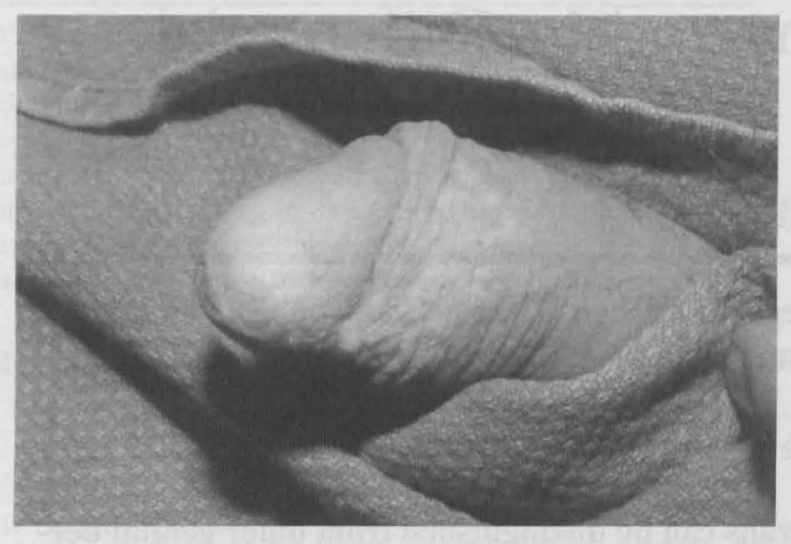

Figure 1. Balanitis xerotica obliterans. Well-defined, hypopigmented patch on the distal glans. Sclerotic process extends to urethral meatus with mild erythema of urethral os. Multiple hypopigmented macules, coalescing into plaques, are present on retracted foreskin.

\section{Discussion}

Balanitis xerotica obliterans is a chronic, sclerotic dermatitis involving the genital skin of men. When it occurs at sites other than the penis, it is called lichen sclerosus et atrophicus. Clinically, patients with balanitis xerotica obliterans develop discrete, angular, white, atrophic macules and patches on the glans, prepuce, and foreskin of the penis, with only rare involvement of the shaft. The prepuce is often thickened, and fissures and erosions appear over the glans. Because the atrophic sclerotic lesions can be quite sensitive to trauma, bullae, shallow erosions, and bleeding are sometimes observed. Phimosis, the inability to retract the foreskin over the corona of the penis, and paraphimosis, the inability to extend the foreskin over the glans, are potential sequelae. Balanitis xerotica obliterans is found most commonly in patients aged between 15 to 50 years who are uncircumcised or who had circumcisions later in life. It tends to progress slowly and insidiously for an extended period and can be accompanied by pruritus, tenderness, painful erections, dysesthesia, dysuria, and a reduction in the force of urine flow.

These symptoms can be quite troubling for a patient and often prompt his visit for medical attention. Despite considerable clinical transformation and damage, however, some patients can remain asymptomatic.

Although the cause of balanitis xerotica obliterans is unknown, autoimmune, hormonal, keratin, collagenase, elastase, and genetic factors are all im plicated. Balanitis xerotica obliterans is diagnose definitively by histologic evaluation of a cutaneou biopsy. Affected tissues display variable hyperkeraê tosis, parakeratosis, epidermal atrophy, liquefac 0 tion, degeneration of the basal layer, flattening oै the rete pegs, homogenization of collagen in the der mis, and a sparse dermal mononuclear cell infiltrate

Given the clinical appearance of balanitis xe응 rotica obliterans, the differential diagnosis include $\frac{\overline{\bar{c}}}{\overline{7}}$ genital herpes, syphilis, fixed drug eruption, vitil@ igo, Reiter syndrome, squamous cell carcinoma and erythroplasia of Queyrat. (Table 1) $\vec{\circ}$

Genital herpes simplex virus (HSV) infection is $\frac{\omega}{N}$ sexually transmitted disease classically described $\frac{N}{20}$ grouped vesicles on an erythematous base associ $\frac{0}{3}$ ated with HSV type $2 .^{2}$ Vesicles generally rang: from 2 to $4 \mathrm{~mm}$ and are distributed over the glansos prepuce, and shaft. Because the vesicles are fragile patients infrequently come to their primary care provider with intact lesions; more commonly, the lesions consist of shallow erosions. Primary genita@ herpes is associated with a severe cutaneous erup $\stackrel{\Phi}{3}$ tion and fever and symptoms of headache, malaise myalgias, and arthralgias. Recurrent genital herpe infections are generally less severe and might no@ produce systemic symptoms. A suspected diagnosi of genital herpes infection can be confirmed by the evaluation of a tissue scraping from the base of aro erosion, a positive Tzanck smear with multinucle $\frac{\mathscr{Q}}{2}$ ated giant cells, or a positive rapid fluorescent an흠 tibody test specific for herpes simplex.

Syphilis is a sexually transmitted disease cause by the spirochete, Treponema pallidum. Primarys syphilis usually appears at the corona of the penis as a painless chancre consisting of a central ulcer wittg raised edges. These early lesions generally regres after several weeks. The resolving primary chancro looks like an atrophic macule or patch, mimickingo balanitis xerotica obliterans. Syphilis is diagnosed心 by identifying the spirochete with dark-field mi $\frac{D}{0}$ croscopy or by serologic studies. Nonspecific sero logic tests that use a nontreponemal antigen are tho rapid protein reagin test and the VDRL test. A: false-positive results occur (most commonly in cole lagen vascular disease), a specific treponemal antigen test (FTA-Abs) will confirm the diagnosis of syphilis.

A fixed drug eruption is a recurrent allergio reaction to an ingested substance. Both skin ancog mucous membranes can be involved. In order of 
Table 1. Characteristics of the Differential Diagnosis of Balanitis Xerotica Obliterans.

\begin{tabular}{|c|c|c|c|c|}
\hline Disease & Systemic Symptoms & Extragenital & Cause & Diagnosis \\
\hline $\begin{array}{l}\text { Balanitis xerotica } \\
\text { obliterans }\end{array}$ & No & Occasionally & Unknown & Biopsy \\
\hline $\begin{array}{l}\text { Herpes simplex virus } \\
\text { (HSV) }\end{array}$ & $\begin{array}{l}\text { Fever, myalgia, } \\
\text { headache, malaise }\end{array}$ & Yes & $\begin{array}{l}\text { HSV type 2, HSV type } 1 \text { (less } \\
\text { frequently) }\end{array}$ & $\begin{array}{l}\text { Tzanck smear, } \\
\text { immunofluorescence, viral } \\
\text { culture, biopsy }\end{array}$ \\
\hline Syphilis & $\begin{array}{l}\text { Splenomegaly, fever, } \\
\text { lymphadenopathy }\end{array}$ & $\begin{array}{l}\text { Secondary: palms, } \\
\text { soles, trunk, neck }\end{array}$ & Treponema pallidum & $\begin{array}{l}\text { Dark-field microscopy, VDRL } \\
\text { or rapid protein reagin } \\
\text { followed by FTA Abs }\end{array}$ \\
\hline Fixed drug eruption & No & $\begin{array}{l}\text { Oral mucosa can be } \\
\text { positive of } \\
\text { negative }\end{array}$ & $\begin{array}{l}\text { Drugs, phenolphthalein, } \\
\text { sulfonamides, tetracycline, } \\
\text { ampicillin, nonsteroidal anti- } \\
\text { inflammatory medications }\end{array}$ & $\begin{array}{l}\text { History and physical } \\
\text { examination }\end{array}$ \\
\hline Reiter syndrome & $\begin{array}{l}\text { Arthritis, } \\
\text { conjunctivitis, } \\
\text { fever }\end{array}$ & Palms and soles & $\begin{array}{l}\text { Unknown } \\
\text { Association with HLA B27 }\end{array}$ & Clinical findings \\
\hline Vitiligo & No & Often generalized & Unknown & Biopsy \\
\hline $\begin{array}{l}\text { Erythroplasia of } \\
\text { Queyrat }\end{array}$ & No & No & $\begin{array}{l}\text { Possibly human papilloma } \\
\text { virus }\end{array}$ & Biopsy \\
\hline
\end{tabular}

FTA Abs-treponemal antigen test specific for Treponema pallidum. HLA-human leukocyte antigen.

frequency, the genitalia, face, and torso are most commonly involved. A bulla on an erythematous base or a painful erosion can be found during physical examination of active lesions.

As the acute phase of the fixed drug eruption resolves, discrete postinflammatory hyperpigmented macules are typically observed. Fixed drug eruption of the male genitalia is usually confined to the glans. Diagnosis is based on a careful history, in which the lesion reappears in the same location and is associated with ingestion of a drug. The more common medications implicated in fixed drug eruption are phenolphthalein (a laxative agent that has been removed from the US market), barbiturates, sulfonamides, tetracycline, ampicillin, and nonsteroidal anti-inflammatory medications. ${ }^{3,4}$

Vitiligo is depigmentation of the skin resulting from the loss of melanocytes. Genital lesions tend to be located on the penile shaft and are not sclerotic, atrophic, or symptomatic. Diagnosis is often made on the basis of finding other hypopigmented lesions. Balanitis xerotica obliterans can also have extragenital involvement, however, and a complete history and physical examination are essential to find all areas of involvement. For patients with lighter skin tones, a Wood lamp (ultraviolet light) can be used to augment depigmented patches. Additionally, biopsy shows the absence of melanocytes without dermal sclerosis or loss of the rete pegs.

Reiter disease, found almost exclusively in men, is classically associated with the triad of arthritis, urethritis, and conjunctivitis. Cutaneous manifestations include circinate balanitis (sharply marginated erosions that can involve the glans, foreskin, shaft, and scrotum) and keratoderma blennorrhagicum (psoriatic-like pustular plaques often noted on the palms and soles). Systemic findings, such as fever and malaise, are common. Diagnosis of Reiter disease is predicated on a seronegative asymmetric arthropathy lasting more than 1 month and one or more of the following: urethritis, cervicitis, dysentery, inflammatory eye disease, or mucocutaneous disease. A complete history and physical examination are of paramount importance, as biopsy findings of Reiter disease are often indistinguishable from psoriasis. The development of Reiter disease is strongly associated with urogenital infections caused by a variety of agents in patients who are positive for human leukocyte antigen B27.

Squamous cell carcinoma of the penis and erythroplasia of Queyrat (squamous cell carcinoma in situ of the glans or prepuce) both must be kept in the forefront of any differential diagnosis of penile lesions because of the serious nature of the disease. Characteristically, squamous cell carcinoma appears as a velvety, red, sharply demarcated plaque. The clinical signs can be quite variable, however, and range from white macules to brown verrucous plaques.

Human papillomavirus has been implicated in invasive squamous cell carcinoma and, to an even greater degree, in squamous cell carcinoma in- 
situ. ${ }^{6}$ Specifically, Papillomavirus type 16 is most closely associated with malignant transformation, and research suggests a role for human papillomavirus in the pathogenesis of squamous cell carcinoma. Definitive diagnosis is made by histologic evaluation of a cutaneous biopsy.

\section{Treatment}

Currently there is no curative therapy for balanitis xerotica obliterans. There are, however, many therapeutic options available to limit involvement and relieve symptoms. High-potency topical corticosteroids (ie, clobetasol $0.05 \%$ ointment) are shown to be effective in women with lichen sclerosus et atrophicus and are currently the treatment of choice for balanitis xerotica obliterans. ${ }^{7,8}$ Alternatively, intralesional corticosteroid injections have been proposed. In cases of urethral involvement and stenosis, meatotomy or urethral dilation might be required. Circumcision can relieve symptoms of phimosis and often results in remission. Alternatively, carbon dioxide laser therapy might be an option should a patient not respond to more conservative treatments. ${ }^{9-11}$ Despite the limitations of the current therapeutic options, reports have shown that balanitis xerotica obliterans is usually restricted to those men who had circumcisions later in life, whereas neonatal circumcision appears to prevent the development of this disorder. ${ }^{12}$ In addition to symptomatic treatment and preventative measures, patients need regular follow-up visits (every 12 months), because squamous cell carcinoma arising from the lesions of balanitis xerotica obliterans has been reported. ${ }^{13,14}$

\section{Conclusion}

Balanitis xerotica obliterans can be distinguished from most other genital dermatoses that mimic it by a careful history, focused review of symptoms, and physical examination. A Tzanck smear and cutaneous biopsy are office-based procedures that, along with a rapid protein reagin test, will provide a definitive diagnosis. Treatment with high-dose topical corticosteroids is aimed at reducing the inflammatory process. Balanitis xerotica obliterans has been associated with additional genital abnormalities, including phimosis and squamous cell carcinoma. Neonatal circumcision reduces its occurrence.

\section{References}

1. Stuhmer A. Balanitis Xerotica Obliterans (post-op erationem) und ihre Beziehungem zur Krauros glandis et praeputii penis. Arch Dermatol Syphilogie 1928;156:613.

2. Brugha R, Keersmaekers K, Renton A, Meheus A Genital herpes infection: a review. Int J Epidemion 1997;26:698-709.

3. Pasricha JS. Drugs causing fixed eruptions. Br J Der matol $1979 ; 100: 183-5$.

4. Sharma VK, Dhar S, Gill AN. Drug-related involve ment of specific sites in fixed eruptions: a statistic evaluation. J Dermatol 1996;23:530-4.

5. Hughes RA, Keat AC. Reiter's syndrome and reac tive arthritis: a current view. Semin Arthritis Rheurau 1994;24:190-210.

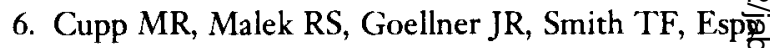
$M J$. The detection of human papillomavirus deoxyri bonucleic acid in intraepithelial, in situ, verrucous. and invasive carcinoma of the penis. J Urol 1995;15 1024-9.

7. Bornstein J, Heifetz S, Kellner Y, Stolar $Z_{0}^{\omega}$ Abramovici H. Clobetasol dipropionate $0.05 \%$ ver? sus testosterone propionate $2 \%$ topical applicatioux for severe vulvar lichen sclerosus. Am J Obstet Gye necol 1998;178(1 Pt 1):80-4.

8. Jorgensen ET, Svensson A. The treatment of phi mosis in boys, with a potent topical steroid (clobe $\vec{b}$ tasol propionate $0.05 \%$ ) cream. Acta Derm Venereo 1993;73:55-6.

9. Hrebinko RL. Circumferential laser vaporization fos severe meatal stenosis secondary to balanitis xerotic obliterans. J Urol 1996;156:1735-6.

10. Kartamaa M, Reitamo S. Treatment of lichen scle rosus with carbon dioxide laser vaporization. $\mathrm{Br} \underset{\Phi}{ }$ Dermatol 1997;136:356-9.

11. Windahl T, Hellsten S. Carbon dioxide laser treat ment of lichen sclerosus et atrophicus. J Urol 1993 150:868-70.

12. Ledwig PA, Weigand DA. Late circumcision and lichen sclerosus et atrophicus of the penis. J Am Acaf Dermatol 1989;20(2 Pt 1):211-4.

13. Pride HB, Miller OF 3rd, Tyler WB. Penile squamous cell carcinoma arising from balanitis xerotica obliterans. J Am Acad Dermatol 1993;29:469-73. హ)

14. Campus GV, Alia F, Bosincu L. Squamous cell care cinoma and lichen sclerosus et atrophicus of the prepuce. Plast Reconstr Surg 1992;89:962-4.

\section{Additional Reading}

Meffert JJ, Davis BM, Grimwood RE. Lichen sclerosus J Am Acad Dermatol 1995;32:393-416.

Lynch PJ, Edwards L. Genital dermatology. New York음 Churchill Livingstone, 1994. 